\title{
EFEITO DE DIFERENTES SANIFICANTES SOBRE A QUALIDADE DE MORANGO CV. OSO GRANDE
}

\author{
Effect of different sanitizing on the quality of strawberry cv. Oso Grande \\ Kelen Cristina dos Reis ${ }^{1}$, Heloisa Helena de Siqueira², Alessandra de Paiva Alves ${ }^{3}$, \\ José Daniel Silva ${ }^{3}$, Luiz Carlos de Oliveira Lima ${ }^{4}$
}

\begin{abstract}
RESUMO
Conduziu-se o presente trabalho para estudar o efeito de diferentes sanificantes, na conservação pós-colheita de morangos, armazenados sob refrigeração $\left(9 \pm 1^{\circ} \mathrm{C}\right.$ e $99 \%$ UR), por um período de 12 dias. O delineamento experimental utilizado foi inteiramente casualizado, com 3 repetições, constituindo dos seguintes tratamentos: T1) Controle, imersão em água destilada, 15 min, T2) imersão em solução de dicloro s. triazinatriona sódica dihidratada (Sumaveg®) a 200 ppm, por 15 min; T3) imersão em solução de peróxido de hidrogênio $10 \%$, por $15 \mathrm{~min}$; T4) imersão em solução de dicloro isocianurato de sódio (Hidrosanß) a 200 ppm, por 15 min. As análises de $\mathrm{pH}, \mathrm{SS}, \mathrm{AT}$, Cor L*a*b e microbiológicas foram realizadas a cada 3 dias. Os processos de sanificação adotados foram eficientes para manter a qualidade de morangos minimamente processados por 12 dias de armazenamento. Verificou-se, no presente trabalho, que o uso de sanificantes foi de fundamental importância para manter baixas as contagens de fungos filamentosos e leveduras dos morangos minimamente processados.
\end{abstract}

Termos para indexação: Fragaria ananassa Duch., Pós-Colheita, Sanificante, Armazenamento.

\section{ABSTRACT}

The aim of this work was to study the effect of different sanitizing in the conservation postharvest of strawberry, stored in $9^{\circ} \mathrm{C}$ and $99 \%$ R.H. for 12 days. The experiment was conducted in completely randomized design, with three replicates, the treatments constituted by: T1) Control, immersion in distilled water; T2) immersion in solution of dychlorine s. triazinatriona sodiumdehydrated (Sumaveg $($ ) at $200 \mathrm{ppm}$, for $15 \mathrm{~min}$; T3) immersion in solution of hydrogen peroxide 10\%, for $15 \mathrm{~min}$; T4) immersion in solution of dychlorine isocianurate of sodium (Hidrosan $\left.{ }^{\circledR}\right) 200 \mathrm{ppm}$, for $15 \mathrm{~min}$. The analyses of pH, SS (soluble solids), TA (titrable acidity), Color $\mathrm{L}^{*} \mathrm{a} * \mathrm{~b}$ and microbiological was evaluated in $0,3,6,9$ and 12 days. The process of sanitizing was efficient to maintain the quality of strawberry minimally processed for 12 days. The use of sanitizing was of fundamental importance to maintain low containing of microorganisms of the group mold and yeasts.

Index terms: Fragaria ananassa Duch, postharvest, sanitizing, storage.

(Recebido em 18 de maio de 2006 e aprovado em 28 de dezembro de 2006)

\section{INTRODUÇÃO}

O morangeiro pertence à família das rosáceas e ao gênero Fragaria. O morango é uma infrutescência de grande aceitação comercial por sua aparência, aroma e sabor atrativo, características que o colocam como uma das mais saborosas sobremesas (HENRIQUE \& CEREDA, 1999).

O morango tem destaque como uma boa fonte de ácido ascórbico e compostos flavonóides. Apesar das excelentes características sensoriais, o morango é muito perecível, possui limitada vida útil pós-colheita, apresenta alta taxa respiratória e suscetibilidade ao desenvolvimento de agentes patogênicos (HENRIQUE \& CEREDA, 1999).
A comercialização e a disponibilidade de morangos são restritas, pela rápida deterioração dos frutos causada pela senescência e doenças pós-colheita, que acarretam perdas consideráveis, tanto nutritivas quanto econômicas.

O processamento mínimo do morango visa manter as características sensoriais e agregar valor aos mesmos, além de inovar conferindo conveniência ao produto, melhorar o manuseio pós-colheita, com conseqüente redução de perdas e também melhora na qualidade do produto (SOUZA, 2005).

A sanificação é uma prática de extrema importância, que contribui para a redução de microrganismos alteradores, para atender aos padrões exigidos pela

\footnotetext{
Engenheira Química, Doutora em Ciência dos Alimentos - Departamento de Ciência dos Alimentos/DCA - Universidade Federal de Lavras/UFLA - Cx P. 3037 - 37200-000 - Lavras, MG - kelen cr@yahoo.com.br

'Engenheira Agrônoma, Doutoranda em Ciência dos Alimentos - Departamento de Ciência dos Alimentos/DCA - Universidade Federal de Lavras/UFLA Cx. P. 3037 - 37200-000 - Lavras, MG - heloisa.elias@yahoo.com.br

${ }^{3}$ Graduandos em Engenharia de Alimentos - Departamento de Ciência dos Alimentos/DCA - Universidade Federal de Lavras/UFLA - Cx. P. 3037 37200-000 - Lavras, MG - alessandra ufla@yahoo.com.br; daniel ufla@yahoo.com.br

${ }^{4}$ Doutor em Ciência dos Alimentos, Professor Adjunto - Departamento de Ciência dos Alimentos/DCA - Universidade Federal de Lavras/UFLA - Cx. P. 3037 - 37200-000 - Lavras, MG - Icolima@ufla.br
} 
legislação e aumentando a vida de prateleira. Também melhora a condição higiênico-sanitária dos alimentos, evitando riscos à saúde do consumidor pela veiculação de patógenos (BRACKETT, 1992).

O uso de sanificantes visa reduzir, até níveis seguros, os microrganismos alteradores de alimentos e eliminar patógenos das superfícies de equipamentos e utensílios que entram em contato com os alimentos e assim, contribuem para a melhor qualidade microbiológica dos alimentos produzidos (SANTOS, 2003).

A escolha e a aplicação adequada do sanificante químico, em frutas e hortaliças minimamente processadas, são fundamentais para a indústria de alimentos. Estes sanificantes variam em sua habilidade de destruir microrganismos. Sua efetividade depende das características físicas e químicas do vegetal, do tipo de microrganismo alvo, do tempo de contato, da concentração e temperatura de solução. Alguns sanificantes são apropriados para o uso em lavagem direta das superfícies dos alimentos inteiros ou processados, outros somente para processos de lavagem com água em equipamentos ou recipientes e aparelhos (ELPHICK, 1998; SAPERS \& SIMMONS, 1998).

Encontram-se disponíveis para a sanificação um grande número de marcas comerciais de compostos à base de cloro e sanificantes alternativos (peróxido de hidrogênio). O cloro é amplamente utilizado na indústria de alimentos em função do custo e da disponibilidade do produto e pela maior atividade germicida; o peróxido de hidrogênio $\left(\mathrm{H}_{2} \mathrm{O}_{2}\right)$ é um forte oxidante devido à liberação de oxigênio, sendo usado como agente bactericida e esporicida (BLOCK, 1991; MACEDO, 2001). A Food and Drug Administration (FDA) aprova o $\mathrm{H}_{2} \mathrm{O}_{2}$, para uso em alimentos. $\mathrm{Na}$ indústria de alimentos é aplicado na esterilização de embalagens, na sanificação de equipamentos e utensílios e na pasteurização de leite (SAPERS \& SIMMONS, 1998).

O dicloro isocianurato de sódio ( $\mathrm{NaDCC}$ ) é um composto clorado orgânico comercializado na forma de pó ou comprimido efervescente. Por atender a um processo de fabricação específico para uso em alimentos, não libera metais pesados e Trihalometano (compostos carcinogênicos), quando hidrolisado. Assim, a substituição dos compostos clorados inorgânicos, como o hipoclorito de sódio, pelo NaDCC, para uso em alimentos já está consolidada, desde a década de 90 nos EUA e Europa (MACEDO, 2001).

O dicloro s. triazinatriona sódica dihidratada apresenta ação antimicrobiana comprovada, é um produto atóxico e atende às exigências da portaria $\mathrm{n}^{\circ} 15$ da Agência
Nacional de Vigilância Sanitária, sendo eficiente para Staphyloccocus aureus e Escherichia coli, classificandose como desinfectante para a indústria de alimentos (CLEVER HIGIENE PROFISSIONAL, 2005).

A temperatura também é um fator de grande importância na preservação da qualidade das frutas e hortaliças, não só pela influência que exerce na atividade respiratória, como também pela sua influência sobre a velocidade de crescimento microbiano e determinação da biota deteriorante. Em geral, baixas temperaturas reduzem a velocidade de crescimento da maioria das bactérias e fungos (ROSA et al., 2000).

Objetivou-se neste trabalho avaliar a qualidade de morangos, cv. Oso Grande, submetidos à imersão com diferentes sanificantes e armazenados sob refrigeração ( $9 \pm$ $1^{\circ} \mathrm{C}$ e $99 \%$ UR), por um período de 12 dias.

\section{MATERIAL E MÉTODOS}

Foram utilizados morangos da cultivar 'Oso Grande', adquiridos no Ceasa/BH e comercializados em Lavras - MG. Os frutos adquiridos foram levados para o Laboratório de Pós-Colheita de Frutas e Hortaliças do Departamento de Ciência dos Alimentos da Universidade Federal de Lavras, UFLA, MG, onde foram selecionados de acordo com a uniformidade de cor, tamanho e ausência de injúrias mecânicas e fisiológicas. Após a retirada do pedúnculo, os frutos foram lavados, novamente selecionados, seguindo os mesmos critérios da primeira seleção, com o intuito de conseguir maior homogeneidade possível, e posteriormente submetidos aos diferentes tratamentos: T1) Controle, imersão em água destilada, 15 min; T2) imersão em solução de dicloro s. triazinatriona sódica dihidratada (Sumaveg®) a 200 ppm, por $15 \mathrm{~min}$; T3) imersão em solução de peróxido de hidrogênio $10 \%$, por 15 min; T4) imersão em solução de dicloro isocianurato de sódio (Hidrosan®) 200 ppm; por $15 \mathrm{~min}$. Após os tratamentos, os morangos "inteiros" foram secos à temperatura ambiente e distribuídos, aleatoriamente, em bandejas de polipropileno seladas com filme de poliéster + polipropileno $60 \mathrm{~mm}$ de espessura, utilizando-se seladora de bandejas - AP340 (TecMaq). Os morangos foram armazenados sob refrigeração $\left(9 \pm 1{ }^{\circ} \mathrm{C}\right.$ e $99 \%$ UR), por um período de 12 dias. A cada 3 dias, as amostras foram retiradas, homogeneizadas separadamente e utilizadas na realização das seguintes análises:

- pH com auxílio de pHmetro (AOAC, 1992).

- sólidos solúveis (SS)- ( ${ }^{\circ}$ Brix), feita usando um refratômetro digital ATAGO PR-100, segundo AOAC (1992).

- acidez titulável (AT) - (\% de ácido cítrico), por titulometria (INSTITUTO ADOLFO LUTZ, 1985). 
- cor $\mathrm{L}^{*} \mathrm{a}$ b, determinada por meio de um colorímetro marca Minolta Ltda., modelo Chroma Meter CR - 3000, sistema L*a*b Color Space, por reflectância. Os parâmetros de cor, medidos em relação à placa de cor branca ( $L=97,02$; $a=5,37$ e $b=-3,63$ ), foram: $L=$ luminosidade [0 (cor preta) a 100 (cor branca) $]$; $a=[-60,0$ (verde) a +60,0 (vermelho)]; b= [-60,0 (azul) a +60,0 (amarelo)].

- análises microbiológicas: coliformes a $35^{\circ} \mathrm{Ce} 45^{\circ} \mathrm{C}$, contagem total de fungos filamentosos e leveduras, segundo ICMSF (1983).

Utilizou-se delineamento inteiramente casualizado, em esquema fatorial 4x5 com 3 repetições (usando 1 bandeja por repetição), sendo 4 tratamentos (Água destilada Controle, Sumaveg ${ }^{\circledR} 200$ ppm, Peróxido de Hidrogênio 10\% e Hidrosan ${ }^{\circledR} 200$ ppm) e 5 períodos de armazenamento (0, 3, 6, 9 e 12 dias).

\section{RESULTADOS E DISCUSSÃO}

Houve efeito significativo da interação, dos tratamentos e do tempo de armazenamento para a variável pH. Os valores de pH variaram de 3,59 a 3,84 (Figura 1). Essa variação demonstra a aceleração do metabolismo do fruto que ocorre durante o seu armazenamento (MENEZES, 1996).

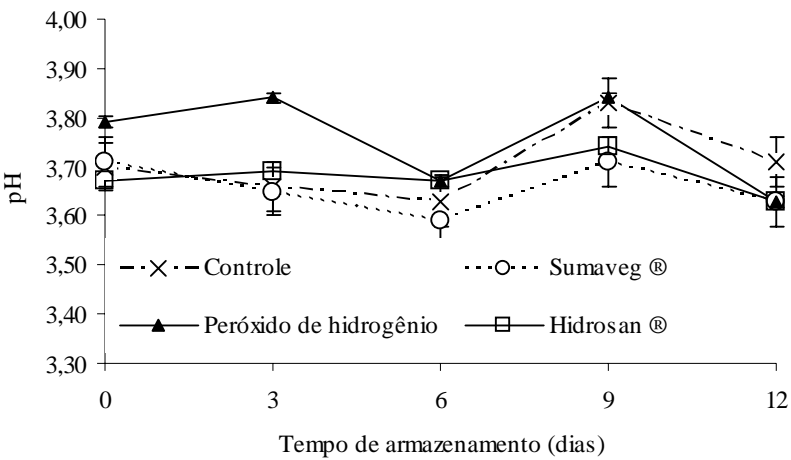

Figura 1 - pH de morangos cv. Oso Grande, tratados com diferentes sanificantes, armazenados a $9 \pm 1^{\circ} \mathrm{C}$ e U.R. $90 \pm$ $1 \%$, por um período de 12 dias.

Estes valores estão próximos aos encontrados por Moraes et al. (2004), onde estudando morango cv. Oso Grande, minimamente processado, encontraram valores variando de 3,66 a 3,70. Berbari et al. (1994) encontraram valores médios de 3,36 estudando a mesma cultivar, valores inferiores ao encontrado neste trabalho.

A influência do pH na ação de sanificantes é um fator que deve ser considerado. De acordo com Santos (2003) a tendência do peróxido em se decompor é maior com o aumento de $\mathrm{pH}$ e, de acordo com este mesmo autor, em pH igual a 3, o peróxido é muito estável e dotado de grande ação esporicida.

O morango tratado com peróxido de hidrogênio apresentou um pH maior $(3,79)$ com relação aos demais sanificantes, no primeiro dia de armazenamento, não diferenciando estatisticamente do sanificante Sumaveg ${ }^{\circledR}$, que apresentou um valor de $\mathrm{pH}$ de 3,71. Os morangos tratados com diferentes sanificantes apresentaram diferentes valores de $\mathrm{pH}$, oscilando durante todo o período de armazenamento (Figura 1).

Os teores de sólidos solúveis variaram ao longo do armazenamento (Figura 2), e não foram influenciados pelos diferentes sanificantes. No $3^{\circ}$ dia de armazenamento, houve um ligeiro aumento no teor de sólidos solúveis, mantendose estável no decorrer do armazenamento. Os valores encontrados no presente trabalho estão próximos aos encontrados por Malgarim et al. (2006) que para morango da cv. Camarosa obtiveram 6,40 a 7,48 ${ }^{\circ}$ Brix e Scalon et al. (1996) que, estudando a cultivar Sequóia encontraram valores entre 7,66 e $9,57^{\circ}$ Brix.

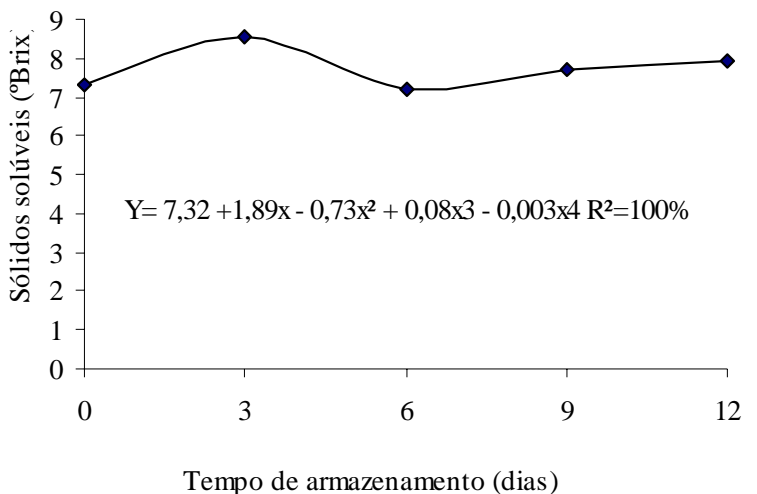

Figura 2 - Teor de sólidos solúveis ( ${ }^{\circ}$ Brix) de morangos cv. Oso Grande, tratados com diferentes sanificantes, armazenados $9 \pm 1^{\circ} \mathrm{C}$ e U.R. $90 \pm 1 \%$, por um período de 12 dias.

Os teores de acidez titulável apresentaram grandes variações no decorrer do armazenamento (Figura 3). Os valores obtidos neste trabalho $(1,19$ a 1,62$)$, estão próximos da faixa descrita na literatura, entre 0,42 a 1,42 (BERG, 1997; SCALON et al., 1996; WILLS et al., 1987). Resultados inferiores (0,82 a 0,86\%) foram relatados por Moraes et al. (2004), em trabalho com a mesma cultivar de morangos minimamente processados.

A acidez, em produtos minimamente processados, é benéfica sob o ponto de vista microbiológico, pois inibe o crescimento de patógenos nocivos à saúde humana, de tal forma que não comprometa a qualidade sensorial deste mesmo produto (MATTIUZ et al., 2004). 


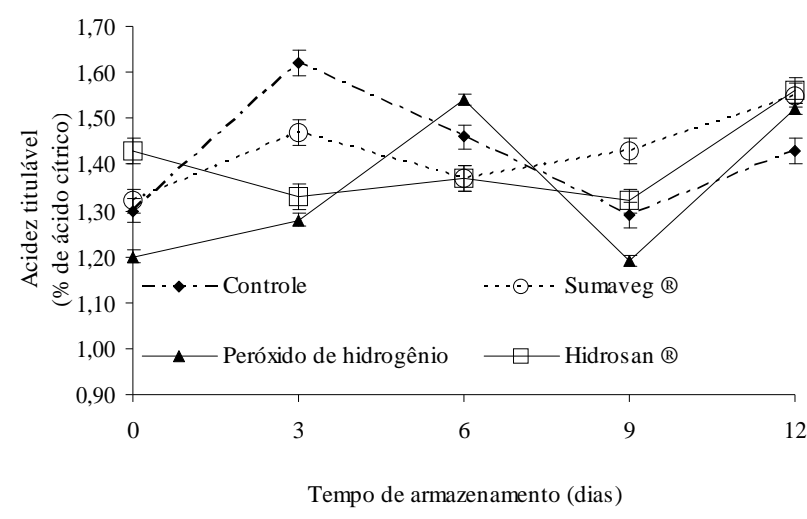

Figura 3 - Acidez titulável (\% de ácido cítrico) de morangos cv. Oso Grande, tratados com diferentes sanificantes, armazenados $9 \pm 1^{\circ} \mathrm{C}$ e U.R. $90 \pm 1 \%$, por um período de 12 dias.

O parâmetro de Cor L* foi afetado pela interação entre tratamento e tempo de armazenamento. Na coloração das frutas ocorreu diferença significativa somente no período zero de armazenamento, não apresentando variação no decorrer de todo o armazenamento (Tabela 1).

Ao final do armazenamento, não se notaram mudanças na cor dos frutos, que mostraram-se vermelhos durante todo o armazenamento.

Segundo Calegaro et al. (2002), a manutenção da cor dos morangos durante o armazenamento é um atributo de qualidade desejado, pois o escurecimento dos frutos compromete seu aspecto visual e, portanto, sua aceitação pelo consumidor.

Os frutos de cor forte e brilhante são os preferidos, embora a cor, na maioria dos casos, não contribua para um aumento efetivo no valor nutritivo ou qualidade comestível do produto (CHITARRA \& CHITARRA, 1990).

Os valores médios do parâmetro $\mathrm{a}^{*}$ foram significativos somente para o fator tempo de armazenamento (Figura 4). Os valores oscilaram durante o armazenamento, apresentando um decréscimo no $3^{\circ}$ dia de armazenamento, seguido de um aumento até o final do armazenamento. Menos valores a* estão associados com frutos mais verdes e maiores valores para o parâmetro $\mathrm{a}^{*}$ estão associados com frutos mais vermelhos. Os frutos, ao final do armazenamento, tenderam a ficar mais avermelhados, de acordo com a figura 4 , que apresenta-se com um aumento acentuado do parâmetro a*, a partir do $6^{\circ}$ dia de armazenamento.

A avaliação da cor é um importante parâmetro para o produtor, pois é através dela que o produtor pode avaliar se o fruto realmente atingiu ou não condições ideais de comercialização.
Os resultados do parâmetro $b^{*}$ foram significativos somente para o fator tempo de armazenamento (Figura 5). Maiores valores do parâmetro $b^{*}$ estão associados com frutos mais amarelos. Os valores variaram ao longo do armazenamento, apresentando um ligeiro decréscimo no $3^{\circ}, 6^{\circ}$ e $9^{\circ}$ dias, seguido de um aumento no $12^{\circ}$ dia de armazenamento. Malgarim et al. (2006), encontraram valores para o parâmetro $b^{*}$ entre 16,35 e 23,17 , valores próximos aos do presente trabalho $(12,77$ a 19,17$)$.

A Resolução RDC N ${ }^{\circ}$ 12, de 2 de janeiro de 2001, do Ministério da Saúde (BRASIL, 2001), estabelece os padrões microbiológicos sanitários para alimentos, não existindo padrões específicos para os frutos minimamente processados. Esses podem ser inseridos no grupo de alimentos designados como: frutas frescas, in natura, preparadas (descascadas, selecionadas ou fracionadas), sanificadas, refrigeradas ou congeladas, para consumo direto, cuja tolerância máxima, para amostra indicativa é de $5 \times 10^{2} \mathrm{NMP}^{-1}$ ou UFC. $\mathrm{g}^{-1}$ de coliformes a $45^{\circ} \mathrm{C}$ e ausência de Salmonella sp em 25g. Verifica-se, na Tabela 2 , que o morango minimamente processado apresentou ausência de Coliformes para todos os tratamentos inclusive o controle (água destilada) - o que pode comprovar que os cuidados higiênico-sanitários, tomados durante o processamento do produto, são de fundamental importância e podem contribuir para que o mesmo apresente baixa contagem microbiana.

No entanto, quanto à contagem de fungos filamentosos e leveduras verifica-se que é de fundamental importância o uso de sanificantes para inibir seu crescimento (Tabela 2). Todas as amostrascontrole apresentaram grandes contagens de fungos filamentosos e leveduras, o que pode também ser verificado visualmente, principalmente no $12^{\circ}$ dia de armazenamento. A presença de fungos em número elevado é indesejável, quanto à qualidade microbiológica, porque são capazes de produzir grandes variedades de enzimas, que provocam a deterioração de frutos. Além disso, muitos bolores podem produzir metabólicos tóxicos quando estão se desenvolvendo nos alimentos.

Babic \& Wataba (1996), estudando populações microbiológicas em espinafre, relataram que as taxas de leveduras são consideradas baixas quando permanecerem entre $10^{3}$ e $10^{4}$ UFC. ${ }^{-1}$, durante todo o período de armazenamento tanto em ar circulante como sob atmosfera controlada em ambas as temperaturas estudadas. 
Tabela 1 - Valores médios do parâmetro L* de morangos cv. Oso Grande, tratados com diferentes sanificantes, armazenados $9 \pm 1{ }^{\circ} \mathrm{C}$ e U.R. $90 \pm 1 \%$, por um período de 12 dias.

\begin{tabular}{lcccccc}
\hline Sanificante & & \multicolumn{4}{c}{ Tempo de armazenamento (dias) } \\
\cline { 3 - 7 } & & 0 & 3 & 6 & 9 & 12 \\
\hline Controle & Parâmetro L* & $32,37 \mathrm{a}$ & $28,68 \mathrm{a}$ & $31,30 \mathrm{a}$ & $26,99 \mathrm{a}$ & $32,14 \mathrm{a}$ \\
\hline Sumaveg® & Parâmetro L* & $30,95 \mathrm{ab}$ & $28,51 \mathrm{a}$ & $30,83 \mathrm{a}$ & $27,58 \mathrm{a}$ & $32,32 \mathrm{a}$ \\
\hline Peróxido de Hidrogênio & Parâmetro L* & $27,13 \mathrm{bc}$ & $28,67 \mathrm{a}$ & $29,75 \mathrm{a}$ & $28,70 \mathrm{a}$ & $32,40 \mathrm{a}$ \\
\hline Hidrosan@ & Parâmetro L* & $25,89 \mathrm{c}$ & $28,48 \mathrm{a}$ & $31,58 \mathrm{a}$ & $27,84 \mathrm{a}$ & $32,12 \mathrm{a}$ \\
\hline
\end{tabular}

Médias seguidas de mesma letra, na coluna, não diferem significativamente a 5\% de probabilidade, pelo teste Tukey.

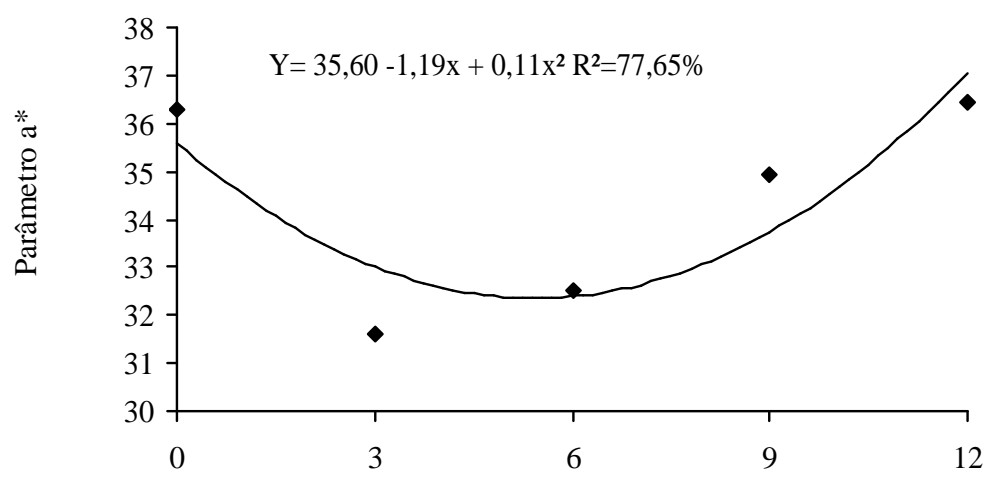

Tempo de armazenamento (dias)

Figura 4 - Valores do parâmetro a* de morangos cv. Oso Grande tratados com diferentes sanificantes, armazenados a $9 \pm 1{ }^{\circ} \mathrm{C}$ e U.R. $90 \pm 1 \%$, por um período de 12 dias.

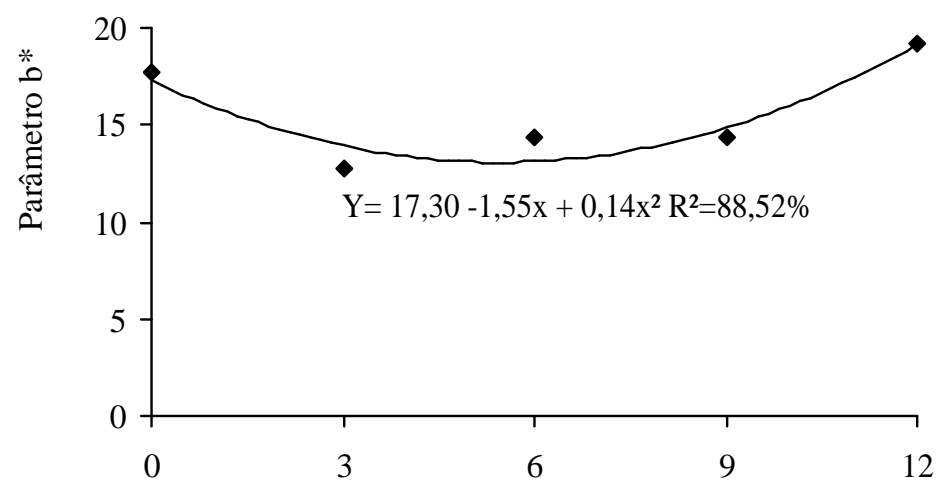

Tempo de armazenamento (dias)

Figura 5 - Valores do parâmetro $b^{*}$ de morangos cv. Oso Grande, tratados com diferentes sanificantes, armazenados $9 \pm$ $1^{\circ} \mathrm{C}$ e U.R. $90 \pm 1 \%$, por um período de 12 dias. 
Tabela 2 - Valores médios de contagens de coliformes a $35^{\circ} \mathrm{C}$, coliformes a $45^{\circ} \mathrm{C}$ e fungos filamentosos e leveduras, em morango cv. Oso Grande, minimamente processado em função do uso de diferentes sanificantes.

\begin{tabular}{|c|c|c|c|c|}
\hline Sanificantes & $\begin{array}{l}\text { Tempo } \\
\text { (Dias) }\end{array}$ & $\begin{array}{l}\text { Coliformes a } 35^{\circ} \\
\left(\mathrm{NMP} \mathrm{g}^{-1}\right)\end{array}$ & $\begin{array}{l}\text { Coliformes a } 45^{\circ} \\
\quad\left(\mathrm{NMP} \mathrm{g}^{-1}\right)\end{array}$ & $\begin{array}{c}\text { Fungos Filamentosos e } \\
\text { Leveduras (UFC } \mathrm{g}^{-1} \text { ) }\end{array}$ \\
\hline \multirow{5}{*}{ Controle } & 0 & ausência & Ausência & $1,08 \times 10^{3}$ \\
\hline & 3 & ausência & ausência & $1,09 \times 10^{3}$ \\
\hline & 6 & ausência & ausência & $1,38 \times 10^{3}$ \\
\hline & 9 & ausência & ausência & $4,25 \times 10^{3}$ \\
\hline & 12 & ausência & ausência & $>300$ \\
\hline \multirow{5}{*}{ Sumaveg® } & 0 & ausência & ausência & $<30$ \\
\hline & 3 & ausência & ausência & $<30$ \\
\hline & 6 & ausência & ausência & $<30$ \\
\hline & 9 & ausência & ausência & $<30$ \\
\hline & 12 & ausência & ausência & $<30$ \\
\hline Sanificantes & $\begin{array}{l}\text { Tempo } \\
\text { (Dias) }\end{array}$ & $\begin{array}{l}\text { Coliformes a } 35^{\circ} \\
\left(\mathrm{NMP} \mathrm{g}^{-1}\right)\end{array}$ & $\begin{array}{l}\text { Coliformes a } 45^{\circ} \\
\left(\mathrm{NMP} \mathrm{g}^{-1}\right)\end{array}$ & $\begin{array}{l}\text { Fungos Filamentosos e } \\
\text { Leveduras (UFC } \mathrm{g}^{-1} \text { ) }\end{array}$ \\
\hline \multirow{5}{*}{ Peróxido de Hidrogênio } & 0 & ausência & ausência & $<30$ \\
\hline & 3 & ausência & ausência & $<30$ \\
\hline & 6 & ausência & ausência & $<30$ \\
\hline & 9 & ausência & ausência & $<30$ \\
\hline & 12 & ausência & ausência & $<30$ \\
\hline \multirow{5}{*}{ Hidrosan $®$} & 0 & ausência & ausência & $<30$ \\
\hline & 3 & ausência & ausência & $<30$ \\
\hline & 6 & ausência & ausência & $<30$ \\
\hline & 9 & ausência & ausência & $<30$ \\
\hline & 12 & ausência & ausência & $<30$ \\
\hline
\end{tabular}

\section{CONCLUSÃO}

Todos os sanificantes adotados foram eficientes para manter a qualidade de morangos minimamente processados, por 12 dias de armazenamento. E o uso de sanificantes foi de fundamental importância, mantendo baixas as contagens de fungos filamentosos e leveduras.

\section{REFERÊNCIAS BIBLIOGRÁFICAS}

ASSOCIATION OF OFFICIAL ANALITICAL CHEMISTS. Official methods of analysis of the Association of Agricultural Chemists. 12. ed. Washington, DC, 1992. 1015 p.

BABIC, I.; WATABA, A. E. Microbial population of freshcut spinash leaves affected by controlled atmospheres.
Postharvest Biology Technology, Amsterdam, v. 9, p. 187 193, 1996.

BERBARI, S. S. G.; NOGUEIRA, J. N.; PASSOS, F. A. Determinação das características físicas, químicas e organolépticas de novas variedades de morango para congelamento. Boletim SBCTA, [S.1.], v. 28, n. 1, p. 18-24, 1994.

BERG, I. J. Potencial de armazenamento e caracterização de frutos de morango cultivares Campinas e Dover colhidos em três estádios de maturação. 1997. $36 \mathrm{f}$. Monografia (Graduação) - Escola Superior de Agricultura “Luiz de Queiroz”, Universidade de São Paulo, Piracicaba, 1997. 
BLOCK, S. S. Peroxygen compounds. In: Disinfection, sterilization and preservation. 4. ed. Philadelphia: Lea \& Febiger, 1991. p. 167 -181.

BRACKETT, R. E. Shelf stability and safety of fresh produce as influenced by sanitation and desinfection. Journal Food Protection, Connecticut, v. 55, p. 808-814, Aug. 1992.

BRASIL. Ministério da Saúde. Resolução RDC n ${ }^{\circ} \mathbf{1 2}$, de 2 de Janeiro de 2001. Brasília, DF: ANVISA, 2001.

CALEGARO, J. M.; PEZZI, E.; BENDER, R. J. Utilização de atmosfera modificada na conservação pós-colheita. Pesquisa Agropecuária Brasileira, Brasília, v. 37, n. 8, p. 1-6, 2002.

CHITARRA, M. I. F.; CHITARRA, A. B. Pós-colheita de frutos e hortaliças: fisiologia e manuseio. Lavras: ESAL/ FAEPE, 1990. 320 p.

CLEVER HIGIENE PROFISSIONAL. Higiene profissional. Disponível em:<http://www.dialever.com.br/produtos _texto.asp?prodID=80>. Acesso em: 20 dez. 2005.

ELPHICK, A. Fruit and vegetable washing systems. Food Processing, Bromley, v. 67, n. 1, p. 22-23, Jan. 1998.

HENRIQUE, C. M.; CEREDA, M. P. Utilização de biofilmes na conservação pós-colheita de morango (Fragaria Ananassa Duch) cv IAC Campinas. Ciência e Tecnologia de Alimentos, Campinas, v. 19, n. 2, maio/ago. 1999.

INSTITUTO ADOLFO LUTZ. Normas analíticas, métodos químicos e físicos para análise de alimentos. 3. ed. São Paulo: Instituto Adolf Lutz, 1985. v. 1, 533 p.

INTERNATIONAL COMISSION ON MICROBIOLOGICAL SPECIFICATIONS FOR FOODS. Técnicas de las analyses microbiológicas. Zaragoza: Acribia, 1983. 430 p.

MACEDO, J. A. B. Subprodutos do processo de desinfecção de água pelo uso de derivados clorados. Juiz de Fora: [s.n.], $2001.67 \mathrm{p}$.

MALGARIM, M. B.; FLORES-CANTILLANO, R. F.; COUTINHO, E. F. Sistemas e condições de colheita e armazenamento na qualidade de morangos cv. Camarosa. Revista Brasileira de Fruticultura, Jaboticabal, v. 28, n. 2, 2006.
MATTIUZ, B. H.; MIGUEL, A. C. A.; NACHTIGAL, J. C.; DURIGAN, J. F.; CAMARGO, U. A. Processamento mínimo de uvas de mesa sem semente. Revista Brasileira de Fruticultura, Jaboticabal, v. 26, n. 2, p. 226-224, 2004.

MENEZES, J. B. Qualidade pós-colheita de melão tipo “Gália” durante a maturação e o armazenamento. 1996. 171 f. Tese (Doutorado em Ciência dos Alimentos) Universidade Federal de Lavras, Lavras, 1996.

MORAES, I. V. M. de; MAMEDE, A. M. G. N.; CENCI, S. A.; SOARES, A. G.; BENEDETTI, B. C.; GODOY, R. L. de O. Influência do tempo de armazenamento e da cultivar na qualidade de morango (Fragaria $x$ ananassa Duch) minimamente processado. In: CONGRESSO BRASILEIRO DE FRUTICULTURA, 18., 2004, Florianópolis. Anais... Florianópolis: UFSC, 2004. CD-ROM.

ROSA, O. D.; CARVALHO, E. P.; DIONÍSIO, F. L.; RIBEIRO, A. C. Presença de Staphylococcus aureus em vegetais minimamente processados. In: CONGRESSO BRASILEIRO DE CIÊNCIA E TECNOLOGIA DE ALIMENTOS, 17., 2000, Fortaleza, CE. Anais... Fortaleza: UFCE, 2000. p. 3.161.

SANTOS, H. P. dos. Influência da sanificação sobre a qualidade de melão (Cucumis melo L) minimamente processado. 2003. 80 p. Dissertação (Mestrado em Ciência dos Alimentos) Universidade Federal de Lavras, Lavras, 2003.

SAPERS, M. G.; SIMMONS, G. F. Hydrogen peroxide disinfection of minimally processed fruits and vegetables. Food Technology, Oxford, v. 52, p. 48-52, 1998.

SCALON, S. P. Q.; CHITARRA, A. B.; CHITARRA, M. I. F.; ABREU, M. S. Conservação de morangos (Fragaria ananassa Duch) cv. Sequóia em atmosfera modificada . Revista Brasileira de Fruticultura, Jaboticabal, v. 18, n. 3, p. 431-436, 1996.

SOUZA, E. C. de. Qualidade de alface americana minimamente processada cv. Raider: efeito do hipoclorito de sódio, peróxido de hidrogênio e ácido ascórbico. 2005. 83 p. Tese (Doutorado em Ciência dos Alimentos) Universidade Federal de Lavras, Lavras, 2005.

WILLS, R. B. H.; LIM, J. S. K.; GREENFIELD, H. Composition of Australian foods: 40. tempere fruits. Food Technology in Australia, Melbourne, v. 39, n. 11, p. 520521, 530, 1987. 